\title{
Improvement and innovation in neurosurgery
}

\author{
Aperfeiçoamento e inovação em neurocirurgia \\ Mauricio Sendeski
}

Charité Universitaetsmedizin Berlin - Institut fuer Vegetative Physiologie.

\section{Correspondence:}

Mauricio Sendeski, Charité Universitaetsmedizin Berlin -

Institut fuer Vegetative Physiologie Charité Platz 1 Berlin 10115 , Germany.

E-mail:mauricio.sendeski@charite. de

Conflict of interest:

There is no conflict of interest to declare.

Received 16 January 2014

Accepted 27 January 2014

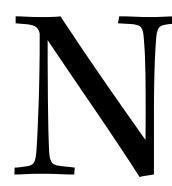
eurosurgery is not an easy job. This is statement is commonsense even among laypeople, as can be noticed by the widespread use of the expression "it's hardly brain surgery" - in the meaning that an apparently complicated task or procedure is actually not as difficult as it may seem to non-experts (another all around idiom with similar meaning is "it's hardly rocket science" - note in both cases the use of the adverb "hardly", not the adjective "hard"). I suspect that most readers of this Journal will agree with the first statement, and the explanation is fairly simple: errors taking place in neurosurgical procedures may have consequences that are far worse in terms of patient morbidity and mortality than what surgeons from other surgical specialties could usually expect.

Correspondingly, in order to keep up to their profession's daily challenge, most neurosurgeons strive throughout life to increase their personal dexterity and technical prowess.

However, just a few neurosurgeons go beyond technical self improvement, and actively try to improve and expand the gamut of therapeutic techniques available to their colleagues - although this is ultimately how surgical fields evolve over time. Importantly, improvement and innovation do not need to start from scratch. For example, Leksell, from the Karolinska Institute (Stockholm, Sweden), had to build upon the fields of stereotaxy and radiotherapy to develop stereotactic radiosurgery ${ }^{1}$. In an more extreme instance, the development of the transphenoidal approach to the sella turcica - first performed with therapeutic purposes by Schloffer in 1907 (Innsbruck, Austria), to treat an hypophisary adenoma ${ }^{2}$ - had strong inspiration from embalming techniques used by ancient Egyptians over 4000 years ago ${ }^{3}$. Such improvements in the therapeutic arsenal of neurosurgeons, however diverse from each other they may appear at fist sight, all have a principle in common: what seemed to others as difficulties and barriers was perceived by innovative surgeons as an opportunity to create something new, something better than what was available to them when they first learned their craft.

The pretemporal craniotomy, as described in this Number of the Arquivos de Neuro-Psiquiatria, by Chaddad-neto et al. ${ }^{4}$ presents us with a typical example of those quantum improvements which mark the history of neurosurgery. Treading the path paved by "larger-than-life" neurosurgical personalities such as Yasargil and Drake, the pretemporal approach expands and complements Yasargil's and Drake's classic signature techniques ${ }^{5,6}$, uniting several of their advantages while overcoming most of their technical drawbacks. The deployment of this access, as reported on this article, has been proved useful to treat both neoplastic as well as vascular diseases, and its potential use is limited only by the skill of the surgeon and her/his ability to discover new uses for it. And while it does not seem fair to expect that every neurosurgeon should become an innovator in her/his field, it seems reasonable to expect that any neurosurgeon should try to deliver her/his patients the best among therapeutic possibilities (and within the limits of her/his abilities). In this sense, this article accomplishes the first step of this process of improving the practice of neurosurgery as whole - by delivering to average neurosurgeons an invaluable set of condensed practical information on an innovative and useful technique.

For those reasons I could not avoid to hope, while I was reading this paper, that if I ever happen to need the services of a neurosurgeon for a pretemporal craniotomy, I would like that she/he have a good reading of this article before deploying the technique on me. It is, after all, really "hard brain surgery". 


\section{References}

1. Leksell L. Stereotactic radiosurgery. J Neurol Neurosurg Psychiatry 1983;46:797-803.

2. Schmidt RF, Choudhry OJ, Takkellapati R, Eloy JA, Couldwell WT, Liu JK. Hermann Schloffer and the origin of transsphenoidal pituitary surgery. Neurosurg Focus 2012;33:5.

3. Fanous AA, Couldwell WT. Transnasal excerebration surgery in ancient Egypt: Historical vignette. J Neurosurg 2012;116:743-748.
4. Chaddad-Net F, Dória-Netto HL, Campos-Filho JM, Reghin-Neto M, Olveira E. Pretemporal craniotomy. Arq Neuropsiquiatr 2014;72:XX-XX.

5. Yasargil MG, Antic J, Laciga R, Jain KK, Hodosh RM, Smith RD. Microsurgical pterional approach to aneurysms of the basilar bifurcation. Surg Neurol 1976;6:83-91.

6. Drake CG. The surgical treatment of aneurysms of the basilar artery. J Neurosurg 1968;29:436-46. 